engine makers of San Recco, near Trieste. The designs struction.
The ship is built according to the newest double bottom system, and is divided into more than one hundred hour, thus greatly diminishing the danger of sinking. The arch armored deck, which is $4 \mathrm{ft}$. below the
water line, closes the lower part of the vessel hermetiwater line, closes the lower part of the vessel hermetiheavy shot: A strong belt of cellulose is fastened to water through openings caused by the shots of an
enemy. The vessel is built entirely of steel. Its chief enemy. The vessel is built entirely of steel. Its chief
dimensions are: Length over all, $341 \mathrm{ft}$., and $321 \mathrm{ft}$. be$19 \mathrm{ft}$. 6 in. ; and it has a displacement of 4,060 tons. The twin screws, each of which is $14 \mathrm{ft}$. 3 in. in diaengines, that can develop $9.800 \mathrm{H}$. P., working at a
speed of 120 revolutions per minute; that is, $244 \mathrm{H}$. $\mathrm{P}$. per ton, a power that has never been attained by any The speed is 19-20 miles per hour. (The engraving
gives a correct idea of the mass of water displaced by the bow, for it is taken from a drawing made from nature.)
The cool water for the condensers is supplied by two powerful centrifugal pumps. There are four double cylindrical boilers, each provided with six arched fire
boxes, which, together, open into 2,664 fire tubes. The boilers are fed by four two-cvlinder double action
punps. Besides these boilers there is a special cylinpumps. Besides these boilers there is a special cylin-
drical high pressure boiler for operating the electric
lighting plant, the hydraulic pumps for the artillery service, the deck pumps, fire apparatus, ventilators, the capstan, etc. The ship can carry 670 tons of coal, which
will take it over a stretch of 4,500 nauticalmiles. A large plant is provided for the electric lights.
There are three dynamos, each of 13,000 volt-amperes, which supply the four search lights each of 20,000 candle power. For lighting the interior of the vessel there
are 350 incandescent lights of 10,16 , and 32 candle power. There is also the Sellner night signaling apparatus. Besides this plant there is a portable Gramme
light machine, which supplies an arc light of 3,000 candle power, and besides the two principal engines The armament of the vessel consists of two Krupp They are mounted on hydraulic carriages and fire barbette, with a range of from $260^{\circ}$ over the bow and
stern to $130^{\circ}$ over each side. There are also six 15 stern to $130^{\circ}$ over each side. There are also six 15
centimeter Krupp guns 35 calibers long, that are arranged at different levels on the sides; ; and then there are two 7 Uchatius guns for the boats and for field ser-
vice. Besides these there are 11 rapid firing guns of 47
and 57 millimeter caliber on board. And finally, there are a number of torpedo projectors which can operate in all directions. This vessel can command a wide ex-
panse of sea, both above and below the water level, and, on account of its great speed, the ease with which

\section{PRESENT AND FUTURE DEVELOPMENTS OF ELECTRICITY.}

By Dr. W. W. JAcQues.*

ELECTRICITY as a science dates back for centuries.
Electricity as an art has been developed within the memory of men still living.

study of electric phenomena and laws for their own sake, independent of the uses to which they may be yut, began when Stephen Gray, nearly two hundred ductors, and thus made the conception of an electric

For a hundred and fifty years af ter that investigators
Fon in the field of electrical science, working largely in the laboratories of the grand old German universities, were
busy finding out how electricity might be produced,
what were its laws of action, how it could be measured and what it was capable of doing.
Thus was the science of electricity built up. Thus was the knowled re gathered together that later should
be put to use. This was the time of plowing and be put to use. This was the time of plowing and
sowing. During the last few years the harvest has begun to come. Now is the time of gleaning.
In the brief half hour allotted to us this evening, I want to view with you the harvest that is being gleaned, cal science places in our hands, and look forward into
the future and see what the fuller harvest is likely to be. knows what electricity is; that, though we know perfectly well many different ways of making it, ways of greater accuracy than we can measure anything else, and though we now use it so generally that it enters And yet recent investigations, carried out in part in And yet, recent investigations, carried out in part in
those domiciles of scientific investigation, the German those domiciles of scientific investigation, the German try, enable us to say with as much accuracy what elec-
tricity is as we can say what those other great forces of nature, sound and light and heat, really are.

When we speak of light, or sound, or heat, we feel
that we are dealing with familiar things-things so familiar to our every day life that it seems useless to try to define or describe them. Every day the sunlight
fills all space; it dazzles our eyes; it falls upon the obthrough the evening, when the sun is gone, we substitute for awhile a gas flame, or a candle, or an electric light, we have then through the day had so much of darkness for our hours of repose.

So, too, from babyhood to old age, all day long and
every day, we are listening to one or another sound friends, or the busy hum of eity * Lectnre delivered before the Deatsche Technische Verein, October 5 , clock at night. Indeed, so constantly are our ears filled
with sounds that when we go alone on to a high moun-
tain, or a desert plain, where there are no trees to rus-
tle with the wind, the silence is painful and oppressive Heat, too

Heat, too, is equally familiar, perhaps even more so, ?he And is not the fireside the very center as well When, however, we speak of that other great force When, however, we speak of that other great force
rom familiar ground, we it is shrouded in mystepy : it is omething we cannot see or hear, something we cannot
asily describe or define. We speak of it in the same easily describe or define. We speak of it in the sam
breath with spirits and with ghosts. The reason, take it, is because the human body has no organ While the eye receives the ray of light, the ear the ray f sound, the presence of

Electricity cannot be seen or heard ; it is tasteless and Subjectively considered, then, electricity eludes our Objectively, however, electricity is as. familiar to us as light, or sound, or heat. Its phenomena have been known. fight and sound. Let us picture to the eye of the Wagination the mechanics of a ray of light.
When we stand out of doors on a cloudless night and ook above us, we see a multitude of stars. The tele-
cope tells us that some of these are suns, some are moons, and some are other worlds than ours.
The

The nearest of them is distant millions of miles, and yet we can see them.
This ching the star at which we are gazing to the eye
This familiarly, a ray of light. Physi cists tell us that along the pathway from the star to our multitude of waves of light.
mach othere

If we turn our eyes to another star, it too sends to of the earth, the same stars send rays of light to us there. And so we find that each of the multitude of waves of light

Between us and the stars, and between the stars ex-
ending everywhere through visible space, is the medtending everywhere through visible space, is the medcrossed continually with countless waves of light-a medium rarer than the rarest gas - the medium that is quids and gases - the ether.

f the ether that everywhere surrounds us and fills all space. By a similar wave motion, but in a coarser
medium, the air sound is transmitted from place to

place.
By means of his vocal organs, a public speaker
ooulds the current of air that issues from his lungsinto in all directions and fall upon the various radiated ears. Something analogous takes place when we drop a
pebble on to the surface of a placid lake. From this
center of disturbance waves of water are radiatedin all center of disturbance waves of water are radiatedin all
directions until they reach the shore. Waves are like-
wise radiated downward to the bottom of the lake, and wise radiated downward to the bottom of the lake, and
fishes have organs, like our ears, that enable them to fishes have organs, like our ears, that
take cognizance of these vibrations.

In the case of waves of water, or waves of sound, or waves of light, we know there is no bodily transference of a particle of water, or air, or ether, from the center
of disturbance to the shore, or ear, or eye. Each particles moves at the most only through a minute fraction next, so that motion, and not matter, is what is transmitted to a distance. Indeed, this propagation of moWho has not seen a wave pass over a field of grain Each particle bows its head but for a few inches,
the wave passes on to the utmost limit of the field. the wave passes on to the utmost limit of the field.
Sound, then, is a wave motion transmitted through the air. Light is a wave motion transmitted through the ether. But both of these media are also capable place through considerable distance.

In the case of air, we call this motion the wind. In the case of the ether, we call it a current of electricity. As wind is the bodily forward motion of the medium. whose vibratory motion we call sound, so a current of Wose vibratory motion we call light.

We may, perhaps, best get a realistic conception of
lectric currents, whether flowing through open space confined to a specesially provided metallic conducting path, by first pieturing to ourselves the phenomena of
of air currents, with which we are more familiar, and of air currents, with which we are more familiar, and
then mentally transferring these phenomena from the
air to the more subtile medium, the ether. The analo-
gies are very striking. and will materially aid the gies are very striking, and will materially aid the In the islands of the Pacific Ocean there is almost In the islands of the Pacific Ocean there is almost
lways a breeze, either from the land to the water or is heated by the sun, its air is rarefied and rises, and the cooler breeze rushes in from the ocean to take its place. At night the island cools, the air descends, and
an outward breeze is produced. There is always a breeze from an area where the air is condensed, and
toward an area where it is rarefied. This local condeward an area where it is rarefied. This local con breezes and winds and hurricanes. The maps issued ways from the one to the other.

If, instead of allowing the wind to blow freely
hrough space, we confine it to a narrow channel, if, for instance, we produce an air pressure at one end of a long iron pipe, we get through the pipe a strong cur-
rent of air, as, for example, in pneumatic tubes, in which the current of air carries along small carriages, our furnaces to the registers, and in the pipess used As an illustration of the enormousvelocitywith which gasometer to the houses about the city where it is
burned. The wind blowing through space is made evident to our eyes by its scatiering of a handful of dry lcaves,
or dust, or bits of paper. It bows and bends the or dust, or bits of paper. It bows and bends the distorted, or instantly blown out. Its direction is more its strength is measured, if we will, by the anemoAs with the wind of nature, so too with the electric wind. If we substitute for our Pacific island a metal ball be represented by the surrounding atmosphere on a
moist day, and produce upon the ball an area of electric tive electric charge, we shall have an electric breeze blowing outward in all directions, which will last so long as the electrification of the ball is above that of
the surrounding air. This may be made evident to the eye by placing upon the ball a handful of bits of paper,
or dry leaves, or dust, any of which will be instantly blown away and dissipated in all directions. If a lighted bent by the breeze, and possibly be blown out.
If, instead of allowing this electric wind to blow If, instead of allowing this electric wind to blow
away in all directions, we confine it to a narrow path; if, for instance, we connect the ball to the earth by a
metallic wire, we get through the wire a strong current
of electricity, whose direction may be determined by the electric weather vane, a magnetic needle, and
whose strength may be measured, not with the anemometer, but by the galvanometer.
It is in currents flowing along metallic wires that the phenomena of electricity have been most carefully have therefore been for the most part utilized in elecNature's wind is used to waft our ships across the
trical inventions. seas, and it is perhaps not a wild idea to conceive of
eleetric repulsion utilized to support and propel heavily laden air ships through the space above our
heads; but it is with electric phenonenta as they have been investigated and utilized up to the present time
that we have to deal in this lecture, and this, as we have seen, means the phenomena of electric currents having through metallic wires.
What are some of these phenomena?

Electricity, or what is the same thing, a current of
ether, passes readily through a copper wire. To the ether current the wire is hollow ; in electrical terms, it
is a good conductor. It also passes quite readily through an iron wire, but not so readily as through cop-
per. It passes still less readily through a wire of car-
bon. It passes more readily through a large wire than bon. It passes more readily through a large wire than
through a small wire. In all wires there is more or less ethereal friction or electric resistance.

In virtue of this ethereal friction or electric resist-
ance, the current heats the wire through which it passes, of course heating a small wire more than a copper, and a carbon wire most of all. We see this in our household system of electric lighting. The current
passes from the central station and throughout our houses to the lamps over comparatively large wires of the lamps it passes through a fine wire of carbon, in
which the friction and consequent heating is so great which the friction and consequent heating is so great that the filament becomes white hot, and were it not removed, it would take fire and disappear.
Again, an electric current flowing in a wire coiled Again, an electric current flowing in a wire coiled
around a bar of iron converts the bar of iron into a magnet, so that it may attract an iron armature placed armature to or from the end of an iron bar around which a wire is coiled, an electric current will be set up
in the same coil ; and by means of the connecting wires in the same coil ; and by means of the connecting wires nishes electricity to be used for light or power. On the former depends the electric motor that propels Again, the electric current flows through wires with
enormous velocity, and consequently it offers an excelenormous velocity, and consequently it offers an excelfor telegraphy. A telegraph wire between two cities
is merely a path through which the current may The "key" is a device by which electricity may be alties of electricity to flow into the line at intervals of ing at their distant end their arrival, we may communicate any ided

The arrival of these little currents of ether may be needle teleyraph, the current passing by a magnetic wind passing a weather vane causes it to point in a given direction.
If it were possible to have on one hill-top a reservoir of air under pressure, or wind, and a key by which small puffs of air could be let out at intervals in accordhill a weather vane, we might thus have a wind tele-
graph operated exactly as is the electric telegraph. But such a telegraph would be slow and cumbersome in operation, and is not likely to come in to general use.
The most modern conception of electricity, then, is The most modern conception of electricity, then, is An electrified body we conceive to be one in which more than a normal amount of this fluid is condensed.
We conceive of an electric current flowing in a wire as a movement of the electric fluid along that wire, exactly as water flows along a pipe.
Electricity has sometimes been called a fourth state of matter ; that is, matter may exist in the solid state, like ice; in the liquid state, like water ; in the gaseous
state, like steam ; and in the ethereal state, electricity. As water is more mobile than ice, and as steam is more As water is more mobile than ice, and as steam is more ubtile than steam. the electric current moves, let me tell you of a message magnet, so that it may attract an iron armature placed
near its end, and thus do mechanical work. The con-
verse of this is equally true, and if we move an iron the former depends the electric motor that propels
our street cars and furnishes power to many of our
industries. lowed to flow into the line. By allowing small quanti- 
that was sent from this city to Australia some years ago. Leaving Boston, it went overland to Nova Scotia, thence under the ocean to the Irish coast, thence across English channel, across the whole continent of Europe and much of that of Asia, again under the ocean to Australia, from which point an

But the telegraph, the telephone, the electric light and the electric railway are old stories to us now. Let us look at some of the things that have been more recently accomplished, and some of the things we may expect electricity to do in the near future. One evening, not many weeks ago, I was invited to
witness some experiments in sending photographs over a wire by means of electricity. You may imagine that of my friend. The laboratory consisted of two rooms. In one was an ordinary photographic camera, a small (n) sufficient size to receive a postal card

From this box two wires stretched across the room to the partition wall and, passing through this, exthe middle of the adjoining room.

I was given an ordinary postal card and asked to "Hrite a short note upon it, and wrote "Good morning," and placed it about six inches in front of the camera, where it was well illuminated by an electric lamp. the plate holder to the developing closet, and presently reappeared with a hastily made negative which he dropped into the slit in the cubical box on the table in ing room and there, issuing from the corresponding box on the table in the middle of the room, was a piece of thin paper the size of a postal card, on which appeared in fac-simile the words I had written, "Good morning," "How do you do?" There would seem to be no reason why the sending and receiving boxes, inone at one end of the wires in Boston and the other at he other end in New York, and thus letters written in the other, and beat the United States mail by six or seven hours.

Another experiment, in which I have taken part only
this last week, was to sit in my office in Boston and talk by long distance telephone with friends in Chicago, more than a thousand miles away. And this, in the same room. Prof. Bell exhibited his then undevelo which, though it whispered only feebly and imperfectly, est marvel hitherto achieved by the electric telegraph."

At the Columbian Exhibition, soon to be held in Chicago, we shall see that invention grown so big that New York. Another invention that must soon come-an inven-
tion whose underlying principles have been already worked out-an invention that is only waiting for some ingenious inventor to make, is a good method of electrother in the midst of a thick fog at sea Let us imagine such a device applied to two ocean greyhounds approaching each other with a combined
velocity of forty miles an hour through a heavy fog in velocity of forty miles an hour through a heavy fog in
a dark night. The lights are useless, for even an eleca dark night. The lights are useless, for even an elec-
tric search light will not be visible a mile away. The
steamer's whistle is useless, for the fog soon absorbs the sound, and yet these two vessels may be rushing im-
mediately toward each other with a force and velocity that in case they meet shall mean total annihilation. But there is no need of such danger. Means of pro-
ducing electrical signals on the one vessel already exist. The ocean is an excellent medium for conducting ist. The ocean is an excellent medium for conducting
these signals to another vessel many miles away, and these signals to another vessel many miles away, and ing such signals may easily be contrived

Let us see how electricity steps in and points out a simple way by which such collisions may be avoided. Suppose each vessel to be equipped with an insulated wire running from bow to stern, but dipping into included in this wire means for producing strong and rapidly alternating currents of electricity. Suppose dinary listening telephone.

Electrical und ulations will be radiated from the first vessel through the wat in in all directions until, reachheard in the listening telephone. By equipping each vessel both with means for sending out electrical undulations and for listening for any that might be received, each vessel would be made But the greatest electrical harvest to be gleaned in the near future will come when some inventor or engineer devises a method of converting the energy stored up in coal directly into electrical energy.
At present we burn coal under a boiler and produce team, then we pass the steam through an engine and produce power, then the power of the engine turns a long chain of expensive machinery, at each link of which there is so great a loss that of 100 pounds of coal burned under a boiler only about five pounds appear
as electricity-a clear waste of 95 per cent. Some day there will be devised an electric generator in which coal is shoveled in at the bottom and electric-
ity taken out at the top, thus using only one piece of ity taken out at the top, thus using only one piece of mechanism instead of the whole chain used at present, It is thus theoretically possible to get twenty times as much electricity out of a ton of coal, and conse quently twenty times as much power, as we do now. Let us see some of the results that would follow.

A transatlantic steamship that now burns 300 tons of coal per day would then burn but fifteen; or, with
the present coal consumption, she would be able to the present coal consumption, she would be able to
cross the ocean in less than two days.
An electric locomotive carrying its own supply of tract and discharge electricity more speedily than anyal and generating its own electricity would be able thing else, and proceeded to make a practical applica\begin{tabular}{l|l} 
tion of the newly discovered truth. About the same \\
time Franklin, on this side of the Atlantic, was receiv-
\end{tabular} two hours.

The machinery of our great manufactories, which now requires to move it work equivalent to that which for one-twentieth of the present cost.

In order to get an idea of the value of such an invenin, let us see what the steam engine has done for us, incient could do.

"Some time before his death in 1819 , while resting the steam engine, when asked to allow his fellow used, saying that he had given employment to the better part of a million of men, and had earned the right hen has his invention given employment?" How immensely has the working power of our people been inreased, and how enormously have the comforts and engine.

The steam engines of the world to-day are doing quire $1,000,000,000$ of men.

In Massachusetts alone there are to-day on our railof $2,000,000$ horses, or $40,000,000$ men. In our factories are steam engines engaged in spinning and weaving I have estimated that were the $60,000,000$ menple $i$ r country all slave holders and all the rest of the world neir slaves, each could not have, without the steam
engine, the comforts and luxuries he has to-day. Attempt now to conceive the benefits of an invenion twenty times as efficient as this, and the figures veight.

THE INVENTOR OF THE LIGHTNING ROD. BY JOSEPH J. KRÁL.

WHEN the newspapers lately announced the names of eminent electricians which are to adorn the Eleccago in 1893 , we were surprised, nay, disappointed, to
find that the respective officials left out the name of a man of science whose merits would fully entitle him to that honor. We mean Prokop.Divis, the man who, before Franklin, discovered the identity of lightning and electricity, and the issuing of electricity from metallic points- two important truths which led him to construct a lightning conductor. But his modesty nearly to be forgotten. The "Encyclopædia Britan-
neaned nica" knows nothing of him, while the German "Con-
versations Lexicon" of Brockhaus (vol. v., page 406) disposes of his two great discoveries exactly in two sh literature is a short sketch in the Historical Magazine for February, 1868 (page 93, article xii.), which of Divis is of itself sufficiently interesting, we hope to to the readers of this magazine. Our article is based pædia of Rieger and Maly (vol. i., pages 209, 211), and Prokop Divis (Dyiv'ish) was born on the 1stof August 1696 , in the town of Zamberk (its German name is
Senftenber), in Northeastern Bohernia, of Bohemia arents. At the gymnasium of $\mathrm{Znojmo}$ he receive tered the Premonstratensian order at Luka. On November 30,1720 , he bound himself with the three moOn account of his high scholarship, he was soon after an account of his high scholarship, he was soon after experiments in physics, with which, contrary to all precedents, he liked to illustrate the subjects dis-
cussed. It will be remembered that the Church has cussed. It will be remembered that the Church has a year had passed, Divis was obliged to change his himself also in this new field, and accordingly, on the erred upon him the degree of doctor of divinity.

imself to scientific research. His wishes seemed to be fulfilled when he was ordained parson of the parish of Moravia, near the city of Znojmo (Znaim on English aps). Here all his leisure was given to physical exof water and fire (oxidation). In 1741 he became prior of the Lukan Convent, and consequently had to disduties of the new office required all his time. Besides, the Austro-Prussian war had just broken out, ${ }^{*}$ and a double care devolved upon the shoulders of the new
prior. Throughout the war Divis faithfully performed he resigned his dignity and returned to Prendice to reume his favorite work. His parish was a small one, and thus Divis was enabled to spare time enough for nation of electricity. Pursuing the safe empiric method, Divis based all his conclusions and estimates torms led him soon to a discovery that lightning was resolved to try if it were possible to make thunderbolts harmless. How thorough his studies were may be heory of atmospheric electricity, a treatise on which Another important discovery followed soon after. Another important discovery followed soon after.
Divis found out that metallic points would both at *Charles VI, King of Bohemia and Hungary and Emperor of Germany
ied in 1740, leaving his dominions to his daughter Maria Theres died in 1740, leaving his dominions to his daughter Maria Theresa.
Frederick the Prrsagian thought this a good opportunity to rob the queen
of some of her territories, and he immediately, without any right, anc
without even a declyration of war, inveded Silesia. ing his first lessons in electricity from Dr. Spence.
The fame of the electrical experiments of Divis soo reached the imperial court of Vienna, and the Empero his experiments in the halls of the imperial repeat These performances were also honored by the presence of the Empress Maria Theresa. The imperial couple were highly pleased with the experiments, and, to show In 1750 Divis demonstrated his superior knowledge of electricity in an amusing way. Father Francis, a with his electrical machine at the Vienna court. While he was making some preliminary remarks, the Bohe-

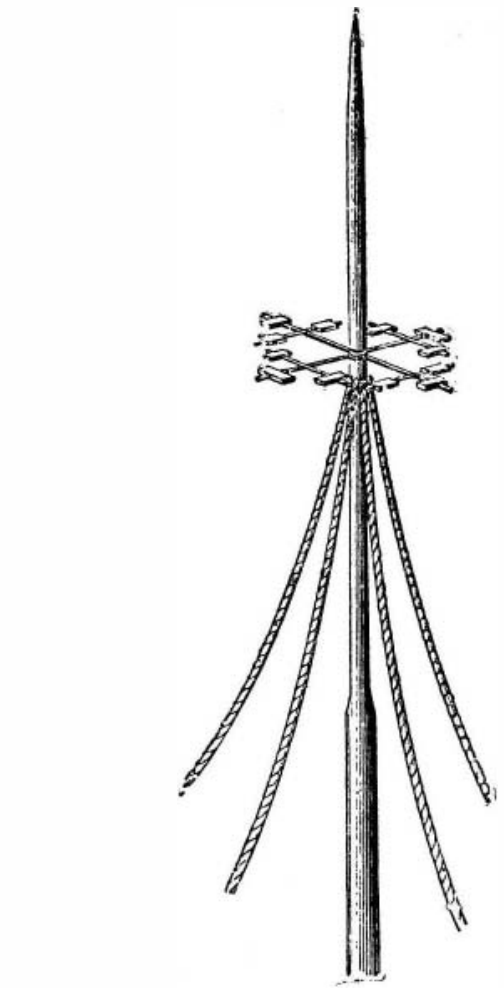

Fig. 1.-THE TOP OF THE LIGHTNING

ROD OF DIVIS.

ron nails in his periwig, approached the machine and viewed it closely from all sides, as though he were going tion was, however, to take away all electricity stored touching the machine. Imagine the horror of Father Francis when he finally came to perform his experiment, and found that, although his accumulators were well insulated, all his electricity was gone !

In 1753 Prof. Richmann, of St. Petersburg, while
bserving a storm from a hut, was killed by lightning observing a storm from a hut, was killed by lightning the purposes of the study. Upon learning of the fate of that martyr of science, Divis drew up a memoir on that the iron bars, as used by Richmann, were both unsafe and dangerous, and clearly showed how, in case averted by means of a conductor, the idea of which had already matured in his mind. This treatise he sent to the famous mathematician and naturalist,
Euler, then President of the Berlin Academy of Sciences, asking for his judgment. But his applicawas in vain ; the academy failed to understand his ers to whom we have to look for any advance in science count of his discovery was read in the British Royal Society, it was laughed at by the connoisseurs. struct his lightning rod. Af ter all that was necessary (5th of prepared, the conductor was erected on th for Divis, in order to avoid all risks, gave up the idea

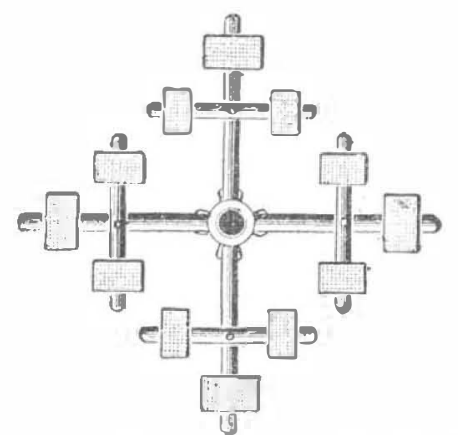

FIG. 2.-A HORIZONTAL VIEW OF THE

CROSS BARS

of placing the lightning rod upon the building, but The lightning rod of Divis was constructed as follows A pointed, slender iron bar formed the main part of the machine. Fastened to it were two cross bars, thus making four arms, across each of which, in turn, a ties so effected bore a box filled with shavings of iron Francis Stephen, who was somewhat of an amateur heavy golden medals with their busts engraved upon which go to show that it is always the individual work-

Divis was not discouraged by the cold reception with 